\title{
Uterine cavities are much smaller than what most gynecologists think
}

In the selection of an appropriate intrauterine device (IUD) little consideration is placed on adequacy of fit. Properly fitting IUDs will likely lead to less adverse effects or patient discomfort resulting in enhanced continuation of use.

We report on a multicenter study conducted at 3 centers Germany and Switzerland in 152 nulliparous women, measuring the maximal width of the uterine cavity using 3D ultrasound.

Measurements were performed by experienced sonographists. The mean width of the uterine cavity in the fundus was $21.6 \mathrm{~mm}$ (range 6.0 - $40.0 \mathrm{~mm}$ ). The median value was $22.0 \mathrm{~mm}$ and the interquartile rang (IQR) 18.0 - $24.8 \mathrm{~mm}$, respectively. Eighty-two $\%$ of women had a uterine cavity width between $15 \mathrm{~mm}$ and $28 \mathrm{~mm}, 40 \%<20 \mathrm{~mm}$ and $6.6 \%<15 \mathrm{~mm}$, respectively (Table 1 , Figure 1).

Uterine cavities in nulliparous women are narrow and rarely wide enough to fit conventional IUDs. Gross discrepancy between the IUD and the uterine cavity leads to side effects (e.g., expulsion, embedment, bleeding, pain) and early discontinuation. Historically, devices too large for the uterine cavity have been routinely inserted which may account for their 5-year continuation rates being only 40 to $50 \%$. The study suggests that $3 \mathrm{D}$ sonography is a precise method to measure the width of the uterine cavity (although 2D may also be suitable) and may result in the selection of a suitable IUD to maximize continuation of use. Measurement of the cavity width is not necessary with a frameless IUD.

\section{Dr. Dirk Wildemeersch, M.D., PhD}

Gynecological Outpatient Clinic and IUD Training Center, Ghent, Belgium

\section{References}

1. Nolte K, Jandi S. Julen O, Hasskamp T, Wildemeersch D. A multicenter study assessing uterine cavity width in over 150 nulliparous women with IUD or seeking IUD insertion using 3D sonography. Clin Obstet Gynecol Reprod Med 2016; 2: 193-8. [Crossref]
Table 1. Maximal fundal width (FUD) in 152 nulliparous women as measured by 3D office sonography

\begin{tabular}{|l|c|}
\hline FUD (mm) & 3D \\
\hline $\mathrm{N}$ & 152 \\
\hline Mean & 21.6 \\
\hline SD & 5.1 \\
\hline Median & 22.0 \\
\hline IQR & $18.0-24.8$ \\
\hline Range & 6.0 - 40.0 \\
\hline $\begin{array}{l}\text { FUD: maximal fundal width; N: number; SD: standard deviation; IQR: inter- } \\
\text { quartile rang; 3D: three-dimensional }\end{array}$ \\
\hline
\end{tabular}

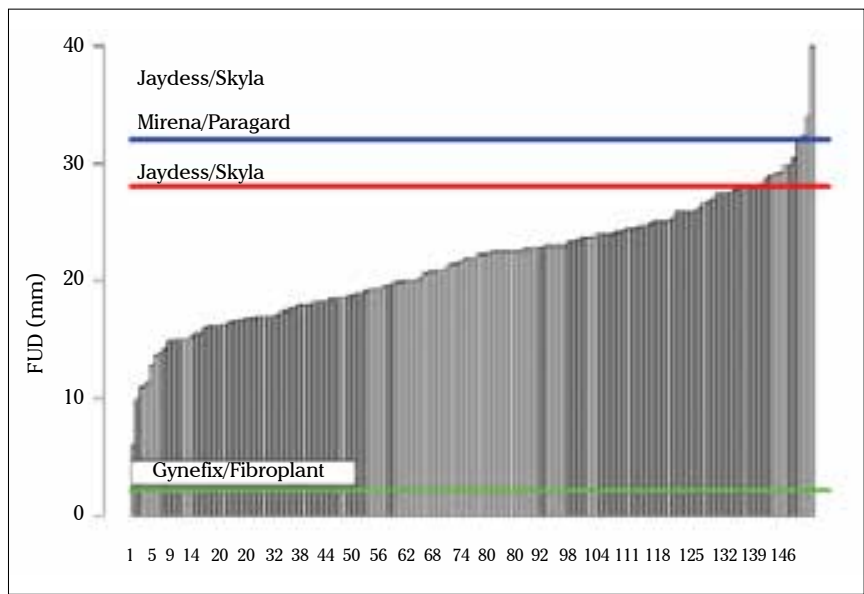

Figure 1. Collated individual maximal fundal widths by 3D sonography in 152 nulliparous women seeking IUD insertion or replacement. For comparison the transverse width for Mirena/Paragard (TCu380A), $32 \mathrm{~mm}$, Jaydess/Skyla, $28 \mathrm{~mm}$, and the frameless GyneFix (copper)/Fibroplant (LNG), 2.2 mm, are included. 